\title{
Effects of alfalfa root exudates on the microbial remediation of nitrate-heavy metal complex pollution in groundwater
}

\author{
Baohua Li ${ }^{\mathrm{a}, \mathrm{c}}$, Yuanjun Dai ${ }^{\mathrm{a}}$, Wenjuan Song ${ }^{\mathrm{c}}$, Xiangliang Pan ${ }^{\mathrm{b}, \mathrm{c}, *}$ \\ a College of Mechanical Engineering, Shanghai Dianji University, Shanghai 201306 China \\ b College of Environment, Zhejiang University of Technology, Hangzhou 310014 China \\ c Xinjiang Institute of Ecology and Geography, Urumqi 830011 China
}

*Corresponding author, e-mail: panxl@zjut.edu.cn

Received 2 Sep 2020

Accepted 28 Mar 2021

\begin{abstract}
The effects of root exudate addition on Fe(II) oxidation, nitrate degradation, and heavy metal removal by Clostridium sp. strain PXL2 were studied. The root exudate addition could increase the average oxidation rate of Fe(II) from 0.52 to $0.68 \mathrm{mM} \mathrm{Fe}(\mathrm{II}) / \mathrm{d}$. The removal rate of nitrate, arsenic, and mercury could be increased from $54 \%$ to $95 \%, 84 \%$ to $99 \%$, and $60 \%$ to $86 \%$, respectively. The complexation of Fe(III) with the root exudates was analyzed by quenching titration. The results showed that there was a complexation of root exudates with Fe(III). This complexation resulted in increased precipitation of iron oxides and further promoted the removal of heavy metals.
\end{abstract}

KEYWORDS: root exudates, heavy metals, groundwater, ferrous oxidizing denitrifying bacteria

\section{INTRODUCTION}

Groundwater is an important water resource used as the main source of water for cities, industry, and agriculture. However, with increasing industrial and agricultural activities, groundwater pollution is expanding from point to surface, from shallow to deep, and from urban to rural areas. Thus, the problem of groundwater pollution has become increasingly prominent [1]. Nitrate-heavy metal complex pollution is a typical type of groundwater pollution. Researchers have conducted numerous studies on this issue [2].

Anaerobic ferrous oxidizing denitrifying bacteria can use nitrate as an electron acceptor for $\mathrm{Fe}(\mathrm{II})$ oxidation in anaerobic environments. The metabolism of this microorganism provides a method for alleviating nitrate-heavy metal complex pollution in groundwater $[3,4]$. Many factors affect the remediation of compound pollution by anaerobic ferrous oxidizing denitrifying bacteria [5], which are related not only to differences in species, but also to the use of organic carbon sources.

Root exudates refer to various organic and inorganic substances released by plant roots in the rhizosphere. Root exudates include cell exfoliates and lysates, high-molecular-weight gels, and low-molecular-weight organic compounds [6]. Re- searches have shown that root exudates are of great significance for the removal of pollutants because they change the solubility and mobility of metal ions in the environment [7]. The removal rate of $\mathrm{Cr}(\mathrm{VI})$ can be increased when maize root exudates are used as a carbon source [8]. Montiel-Rozas et al [9] found that root exudates can regulate the bioavailability of heavy metals. Low-molecular-weight organic acids play an important role in heavy metal fixation. Habibul et al [10] found that root exudates can provide a carbon source for microorganisms in plant-microbial fuel cells. Bioelectrochemical reduction and removal of $\mathrm{Cr}(\mathrm{VI})$ have been achieved using biofuel cells. With the leaching of rainwater and the continuous erosion of groundwater, root exudates are gradually released into the groundwater becoming an important part of the groundwater ecosystem. The relationship between root exudates and the migration and transformation of heavy metals in the groundwater environment has become a concern.

In this study, a typical Clostridium sp. strain PXL2, with ferrous oxide denitrification ability, was isolated from the sediments of natural water bodies in Xinjiang. The Clostridium sp. strain PXL2 could effectively and simultaneously remove As(III) and nitrate from water owing to its $\mathrm{Fe}(\mathrm{II})$ oxidation and denitrification activities [11]. The common plant 
alfalfa was selected as the studied object to analyze the role of root exudates in the microbial degradation of pollutants. This study lays a foundation for the application of oxidative denitrifying bacteria in the field of complex groundwater pollution treatment.

\section{MATERIALS AND METHODS}

\section{Simulated experiment}

The microorganisms used in the experiment originated from an enriched solution of Clostridium sp. strain PXL2, which was isolated and purified in our laboratory. The alfalfa used in the experiment was collected from farmland in the suburbs of Urumqi, Xinjiang, and healthy plants were selected as subjects. The roots of the selected plants were cleaned with tap water, rinsed with deionized water several times, placed in a clean beaker, cultivated in a plant incubator with deionized water for $48 \mathrm{~h}$, and then removed. The culture solution was filtered through a $0.45 \mu \mathrm{m}$ filter and stored at a low temperature in the dark until later use.

The bacterial solution in the stationary growth phase was inoculated into a culture medium consisting of $0.28 \mathrm{~g}$ ammonium chloride, $0.25 \mathrm{~g}$ dipotassium hydrogen phosphate, $0.10 \mathrm{~g}$ magnesium sulfate, $0.01 \mathrm{~g}$ calcium chloride, $0.10 \mathrm{~g}$ yeast extract, $0.50-2.00 \mathrm{~g}$ potassium nitrate, $0.20-1.00 \mathrm{~g}$ ferrous chloride tetrahydrate, and $1000 \mathrm{ml}$ deionized water. The inoculation amount was $5 \%(\mathrm{v} / \mathrm{v})$. The $\mathrm{pH}$ of the medium was 6.8-7.0. All the chemicals were analytically pure (China National Pharmaceutical Group Chemical Reagent Co., Ltd.).

The culture was inoculated at a cell density of about $6 \times 10^{5}$ cells per milliliter to the abovementioned liquid medium containing various concentrations of $\mathrm{Fe}(\mathrm{II})$ and $\mathrm{NO}_{3}^{-}$. Four levels of root exudates addition were designed. Less than $3 \mathrm{ml}$ of samples were collected every $24 \mathrm{~h}$ to determine the concentrations of nitrate, nitrite, and Fe(II). All experiments were carried out in the G250 anaerobic workstation (Don Whitley Scientific, West Yorkshire Shipley, England) and triplicated.

Arsenic (As) and mercury $(\mathrm{Hg})$ were added to the medium to simulate heavy metal pollution. Sodium arsenite and high mercury chloride were selected to simulate arsenic and mercury pollutions, respectively. The sodium arsenite and high mercury chloride were of premium grade purity (China National Pharmaceutical Group Chemical Reagent Co., Ltd.). The initial concentration of arsenic was $36.0 \mu \mathrm{M}$, and the initial concentration of mercury was $0.5 \mu \mathrm{M}$. Approximately, $5-50 \%$ (v/v) of root exudates were added to the medium. The supernatant was collected as samples to detect dissolved As and $\mathrm{Hg}$ in the water.

\section{Analytical methods}

The molecular weight characteristics of the root exudates were analyzed by high-performance liquid chromatography (Superdex TM 20010/300GL, General Electric Company, United States). The exclusion column was washed with a buffer solution ( $9.0 \mathrm{mM}$ sodium chloride and $0.9 \mathrm{mM}$ disodium phosphonate), which was also used as the carrier fluid. The washing rate and the carrier current rate were $0.8 \mathrm{ml} / \mathrm{min}$ and $0.5 \mathrm{ml} / \mathrm{min}$, respectively. 14.4-97.4KDa complex proteins were used as internal standards.

The fluorescence characteristics of the root exudates were measured using a molecular fluorescence spectrophotometer (F-7000, Hitachi, Japan). The parameters were set as follows:- bandpass: excitation $(\mathrm{Ex})=5 \mathrm{~nm}$, emission $(\mathrm{Em})=10 \mathrm{~nm}$; response time: $0.5 \mathrm{~s}$; and scanning speed: $1200 \mathrm{~nm} / \mathrm{min}$. The Ex wavelength range was $200-450 \mathrm{~nm}$ (at intervals of $5 \mathrm{~nm}$ ), and the Em wavelength range was 200$550 \mathrm{~nm}$ (at intervals of $2 \mathrm{~nm}$ ). The measured results were deduced from the experimental blank.

A spectrophotometer (DU $800 \mathrm{UV} /$ Vis Spectrophotometer, Beckman Coulter, United States) was used to measure the concentrations of nitrate, nitrite, and Fe(II). The nitrate concentration was determined at 220 and $275 \mathrm{~nm}$ [12]. The nitrite concentration was monitored at $540 \mathrm{~nm}$ by the formation of purple azo compounds [13]. The Fe(II) concentration was measured using phenanthroline at $510 \mathrm{~nm}$ [14]. For the modified phenanthroline assay, the samples were mixed with $40 \mathrm{mM}$ sulfamic acid ( $\mathrm{pH}$ of approximately 1.8) instead of $25 \%(\mathrm{v} / \mathrm{v})$ hydrochloric acid, as sulfamic acid could react rapidly with nitrite, while preventing Fe(II) oxidation by nitrite at an acidic $\mathrm{pH}$ [15]. The As and $\mathrm{Hg}$ concentrations were measured using an AFS$8 \mathrm{X}$ atomic fluorescence spectrophotometer (Jitian Instruments Co., Ltd., Beijing, China).

\section{RESULTS AND DISCUSSION}

\section{Characteristic analysis of root exudates}

The molecular weight distribution of the root exudates was analyzed using liquid chromatography. The peak time was based on the size exclusion signal. The peak times of the protein standards were 20.14, 30.77, 43.53, 51.66, 60.17, and $70.03 \mathrm{~min}$ 

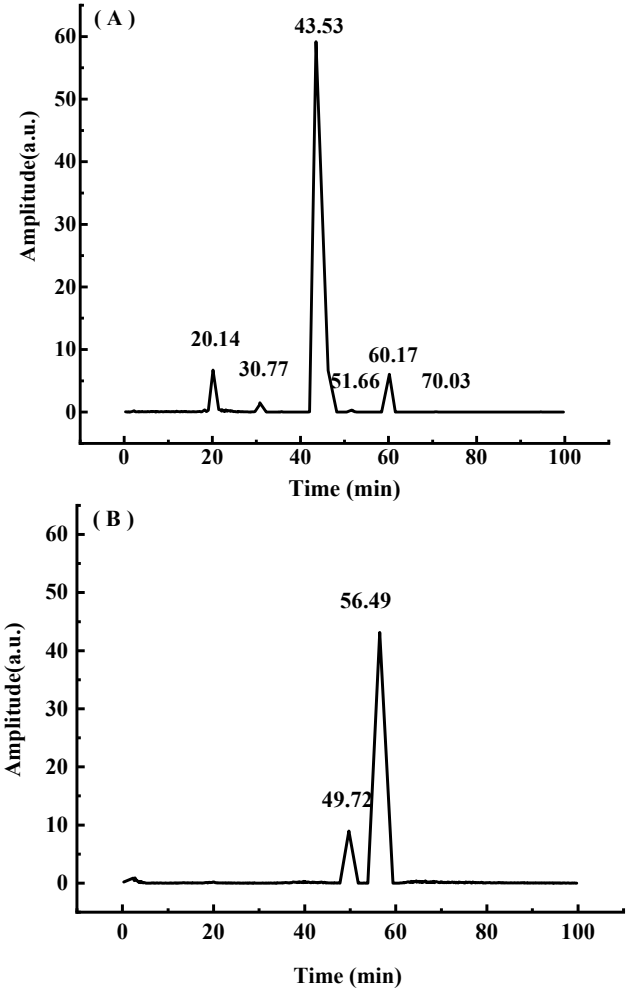

Fig. 1 Liquid chromatograph of protein standards and root exudates: (A) protein standards and (B) root exudates.

(Fig. 1A), and the molecular weights corresponding to the peak times were $97.4,66.2,43.0,31.0$, 20.1 , and $14.4 \mathrm{kDa}$, respectively. The peak times of the root exudates were 49.72 and $56.49 \mathrm{~min}$ (Fig. 1B). The molecular weight distribution of the root exudates was calculated based on the molecular weight of the control protein standard. The main components of the root exudates were substances with molecular weights of $20-31 \mathrm{kDa}$.

The three-dimensional fluorescence spectra of the root exudates are shown in Fig. 2A. Five distinct fluorescence peaks were detected in the fluorescence spectra. Peaks A and B are the fluorescence peaks of aromatic proteins. According to the positions of the fluorescence peaks, these proteins were derived from tyrosine [16-18]. Peak $\mathrm{C}$ is the fluorescence peak derived from tryptophan. Peaks $\mathrm{D}$ and $\mathrm{E}$ are the fluorescence peaks of humic acids.

\section{Effects of added root exudates on ferrous oxide} and nitrate degradation

The change of the Fe(II) concentration after inoculating Clostridium sp. strain PXL2 in the culture medium with different amounts of root exudates
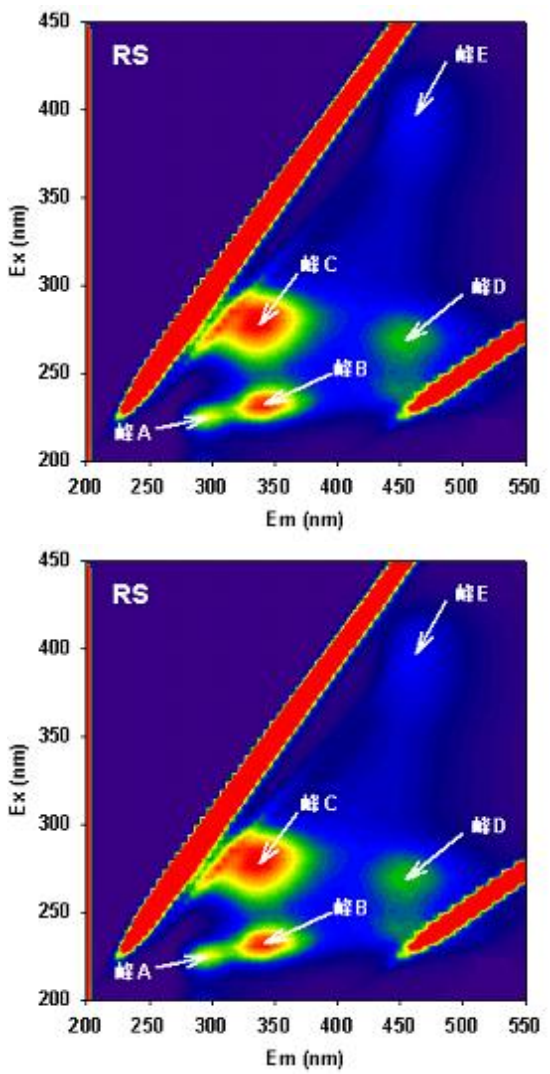

Fig. 2 Excitation-emission matrix (EEM) spectra of root exudates: (A) before interaction with Fe(III) and (B) after interaction with $\mathrm{Fe}(\mathrm{III})$.

is shown in Fig. 3A. The addition of root exudates promoted the oxidation of Fe(II). Without root exudates, the average oxidation rate was $0.52 \mathrm{mM}$ $\mathrm{Fe}(\mathrm{II}) / \mathrm{d}$. The addition of $5 \%$ and $20 \%$ root exudates promoted ferrous oxidation during the first 3 days of the reaction. The concentration of Fe(II) was the same as that without added root exudates by the fifth day. When $50 \%$ root exudates were added, the average oxidation rate increased to $0.68 \mathrm{mM}$ $\mathrm{Fe}(\mathrm{II}) / \mathrm{d}$, which was $30 \%$ higher than that without root exudates. Low-molecular-weight organic acids in the root exudates can be used as a carbon source for microorganisms, thereby promoting the growth and reproduction of microorganisms [19] and accelerating their oxidation of Fe(II). However, some organic acids in the root secretion can be complexed with the Fe(III) formed by the biological oxidation of $\mathrm{Fe}(\mathrm{II})$, hence further promoting the conversion of $\mathrm{Fe}(\mathrm{II})$ to $\mathrm{Fe}(\mathrm{III})$.

With the continuous oxidation of Fe(II), the addition of different concentrations of root exu- 

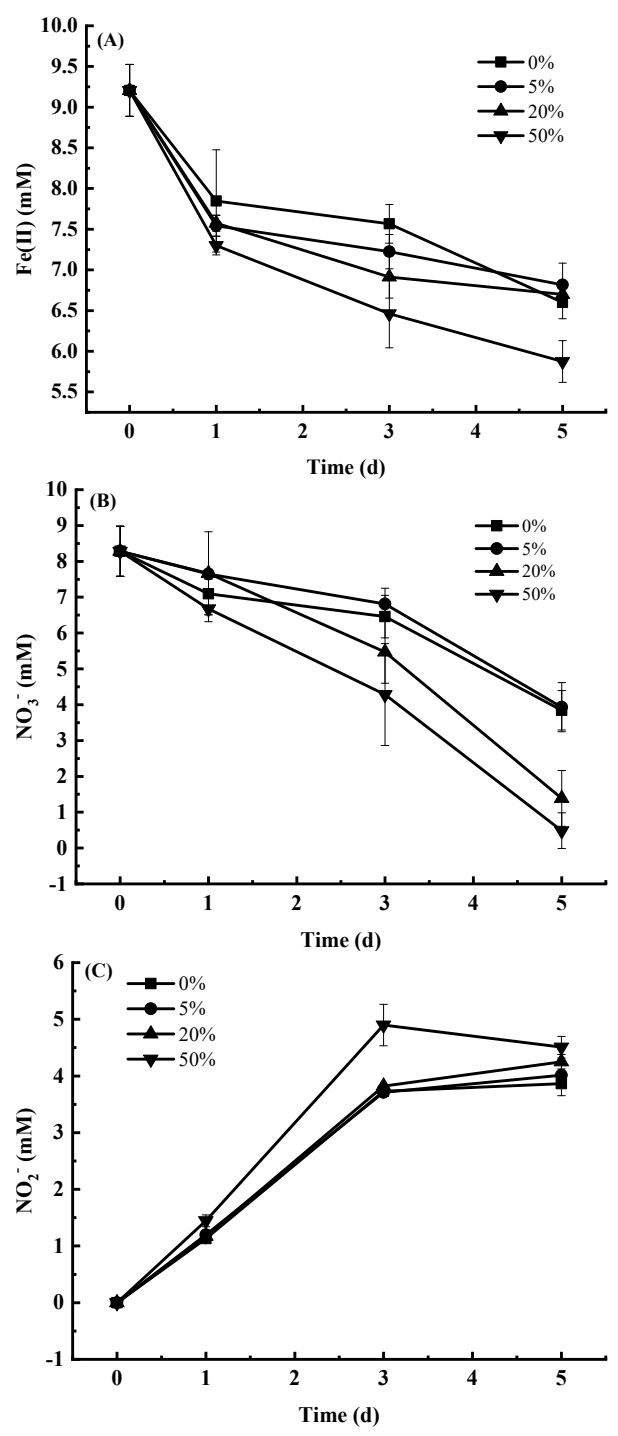

Fig. 3 Time profiles of the $\mathrm{Fe}(\mathrm{II})$, nitrate $\left(\mathrm{NO}_{3}^{-}\right)$, and nitrite $\left(\mathrm{NO}_{2}^{-}\right)$concentrations in the culture of Clostridium sp. strain PXL2 with the stimulation of root exudates.

dates promoted the degradation of nitrate (Fig. 3B). When $5 \%$ root exudates were added, the promotion of nitrate degradation was observed on the first day of culture, and the degradation rate gradually coincided with that of the group without root exudates. This might have occurred because the active ingredients in root exudates that promote nitrate degradation were exhausted. On the fifth day of culture, the nitrate concentration decreased, and approximately $54 \%$ of the nitrate was removed. When $20 \%$ root exudates were added, the nitrate removal promotion effect was clearer. Approximately $83 \%-95 \%$ of the nitrate was removed after 5 days
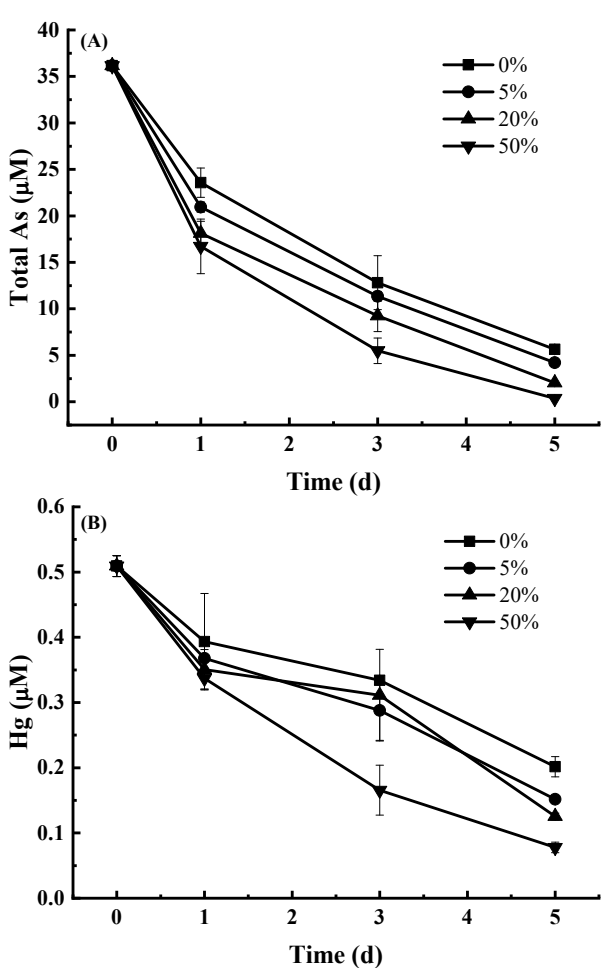

Fig. 4 Time profiles of As and $\mathrm{Hg}$ concentrations in the culture of Clostridium sp. strain PXL2 with the stimulation of root exudates.

of culture.

As nitrate was continuously degraded, nitrite gradually accumulated (Fig. 3C). The accumulated concentration of the culture group with $50 \%$ root exudates was slightly higher than that of the other culture groups, with the highest concentration reaching $4.8 \mathrm{mM}$. As the experiment progressed, the concentration of nitrite gradually stabilized or began to decrease, thereby indicating that nitrite is an intermediate product of nitrate degradation and that nitrite is further used for degradation.

\section{Effects of root exudates on heavy metal removal}

The effects of root exudate addition on heavy metal removal are shown in Fig. 4. When no root exudates were added, the removal rate of As was $84 \%$ after 5 days of inoculation. When $50 \%$ root exudates were added, the As removal rate increased to $99 \%$ (Fig. 4A). Similarly, root exudate addition was beneficial to Hg removal (Fig. 4B). After 5 days of inoculation with $50 \%$ root exudates, the $\mathrm{Hg}$ concentration decreased to $0.07 \mu \mathrm{M}$, and the mercury removal rate increased from $60 \%$ to $86 \%$. 


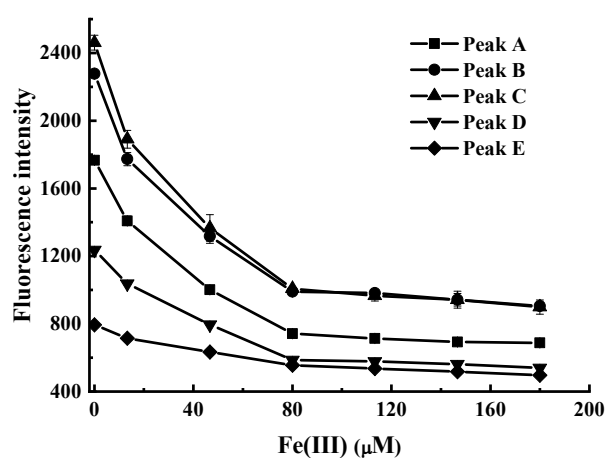

Fig. 5 Fluorescence intensity of root exudates with the increasing concentrations of Fe(III).

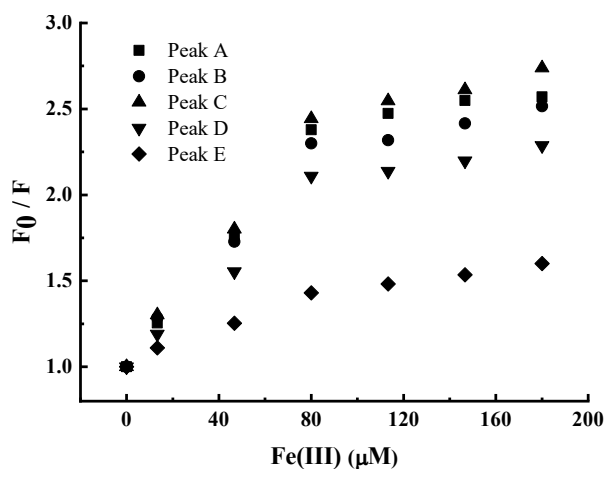

Fig. 6 Plots of $F_{0} / F$ versus [Fe(III)] for root exudates titrated with $\mathrm{Fe}(\mathrm{III})$.

\section{Analysis of the complexing ability between root exudates and $\mathrm{Fe}(\mathrm{III})$}

The complexing ability of the root exudates and $\mathrm{Fe}$ (III) was analyzed by quenching titration (Fig. 2B). In the reaction system, $180 \mu \mathrm{M} \mathrm{Fe(III)}$ fully reacted with the root exudates. The intensity of the fluorescence peaks in the three-dimensional fluorescence spectrum of the root exudates significantly reduced (compared with that in Fig. 2A). Thus, Fe(III) can interact with the fluorescent components in root exudates and effectively quench

Table 1 The conditional stability constants $\left(\log K_{\mathrm{a}}\right)$, complexation constants $\left(\log K_{\mathrm{b}}\right)$, and complexation sites $(n)$ of root exudates fluorophore-Fe(III) systems.

\begin{tabular}{lcccc}
\hline Fluorescence & $\log K_{\mathrm{a}}$ & $\log K_{\mathrm{b}}$ & $n$ & $R^{2}$ \\
\hline Peak A & 4.4144 & 3.0244 & 0.7317 & 0.9732 \\
Peak B & 4.5230 & 2.7218 & 0.6626 & 0.9776 \\
Peak C & 4.5154 & 2.9081 & 0.6956 & 0.9797 \\
Peak D & 4.3028 & 3.0347 & 0.7611 & 0.9750 \\
Peak E & 4.3157 & 0.2893 & 0.6633 & 0.9932 \\
\hline
\end{tabular}

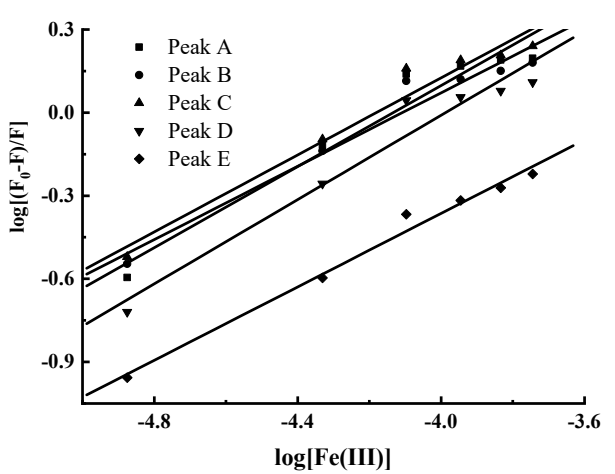

Fig. 7 Modified Stern-Volmer plots of root exudate fluorescence titrated with $\mathrm{Fe}(\mathrm{III})$.

their fluorescence.

The decrease in fluorescence intensity with the increase in $\mathrm{Fe}$ (III) concentration in the solution is shown in Fig. 5. The Stern-Volmer equation was used to fit the fluorescence quenching data, as follows Eq. (1):

$$
F_{0} / F=1+K_{\mathrm{q}} \tau_{0}[Q]=1+K_{\mathrm{SV}}[Q]
$$

where $F_{0}$ is the initial fluorescence intensity, $F$ is the fluorescence intensity after the addition of a quencher, $K_{\mathrm{q}}$ is the quenching rate constant, $K_{\mathrm{sv}}$ is the quenching constant, and $\tau_{0}$ is the average lifetime of the fluorescence emitted by the fluorophore in the absence of a quencher. For biological macromolecules, $\tau_{0}$ is generally $8-10 \mathrm{~s}[20]$. [Q] is the concentration of the quencher.

The curve of the fluorescence intensity of root exudates corresponding to different $\mathrm{Fe}(\mathrm{III})$ concentrations in the solution is shown in Fig. 6. The fluorescence intensity of root exudates exhibited a non-linear change with an increase in the Fe(III) concentration. This feature is significantly different from the typical Stern-Volmer linear curve. This means that the fluorescence quenching of root exudates by Fe(III) involves both dynamic and static quenching [20].

The Stern-Volmer correction equation (2) was used to analyze the fluorescence quenching data. These data can aid the understanding of the fluorescence quenching mechanism.

$$
\frac{F_{0}}{F_{0}-F}=\frac{1}{f K_{\mathrm{a}}(Q)}+\frac{1}{f}
$$

where $f$ is the percentage of fluorescence emitted by the fluorophore that complexes with the quencher and $K_{\mathrm{a}}$ is the effective quenching constant. 
Lakowicz [20] proposed that the initial fluorescence $\left(F_{0}\right)$ contains two parts that are quenchable $\left(F_{0} a\right)$ and non-quenchable $\left(F_{0 \mathrm{~b}}\right)$, as follows:

$$
\begin{gathered}
F_{0}=F_{0 \mathrm{a}}+F_{0 \mathrm{~b}} \\
f=\frac{F_{0 \mathrm{a}}}{F_{0 \mathrm{a}}+F_{0 \mathrm{~b}}}
\end{gathered}
$$

In the presence of a quencher, only $F_{0 a}$ will change. The obtained fluorescence intensity can be used to fit the Stern-Volmer correction equation to calculate the fluorescence quenching parameters. By substituting the fluorescence quenching data of Fe(III) by root secretions into Eq. (2) and fitting the data, the obtained function had a good linear correlation $\left(R^{2}>0.996 ; p<0.0001\right)$. The conditional stability constants $\left(\log K_{\mathrm{a}}\right)$ are given in Table 1 . The conditional stability constants of peaks $\mathrm{A}, \mathrm{B}$, and $\mathrm{C}$ were slightly higher than those of peaks $\mathrm{D}$ and $\mathrm{E}$, thereby indicating that the stabilities of the complexes of Fe(III) with tyrosine and tryptophan are strong, whereas those of the complexes with phytic acid are less stable.

When the equilibrium sites of small molecules and large molecules are combined, the change in the fluorescence intensity of the fluorophores can be substituted into Eq. (5) to calculate the complexation constant $\left(K_{\mathrm{b}}\right)$ and complexation sites $(n)$ of the fluorophores and the quencher molecules [21]:

$$
\log \frac{F_{0}-F}{F}=\log K_{\mathrm{b}}+n \log [Q]
$$

A larger $K_{\mathrm{b}}$ value indicates stronger complexation ability between the fluorophore and the quencher, and a larger value of $n$, a greater the number of quencher molecules that the fluorescent group can complex. The $\log K_{\mathrm{b}}$ and $n$ calculated according to Eq. (5) are given in Table 1. The complexation constant of peak E was significantly lower than those of the other four peaks, thereby indicating that the complexation between humic acids and $\mathrm{Fe}$ (III) represented by peak $\mathrm{E}$ was significantly weaker than those with root exudates derived from tryptophan.

The function fitting curve is shown in Fig. 7, where $\log \left[\left(F_{0}-F\right) / F\right]$ is the dependent variable, and $\log [\mathrm{Fe}(\mathrm{III})]$ is the independent variable. The curve showed a good linear correlation $\left(R^{2}>0.973\right.$; $p<0.001$ ).

Because of their ubiquitous nature, significant metabolic capacities, and related adaptation potentials, microorganisms play a key role in the functioning and transformation of biogeochemical cycles. Processes such as denitrification and nitrogen fixation are specifically related to the activities of microorganisms [22]. The metabolism of microorganisms involved in plant root exudates plays an active role in the geochemical cycle of pollutants.

The involvement of root exudates affects the removal of heavy metals by iron oxides; for example, sunflower root secretions can promote the adsorption of hydrated iron oxide on $\mathrm{Cd}^{2+}$. Studies have also shown that organic acids can help improve the adsorption of cadmium by iron oxides (goethite) $[23,24]$. For example, the presence of different concentrations of citric acid can promote the effect of goethite on $\mathrm{Cd}^{2+}$ [23]. This may occur because $\mathrm{Cd}^{2+}$ can precipitate with organic acids, such as citric acid and oxalic acid.

Other studies have found that organic acids inhibit the adsorption of heavy metals by iron oxides (goethite) [25]. This may occur because organic ligands compete with heavy metal ions for adsorption sites, or because the presence of organic ligands inhibits the hydrolysis of heavy metal ions; thereby reducing the probability of heavy metal adsorption [26].

Some studies have indicated that the presence of organic acids affects the adsorption performance of iron oxide. The inhibition or promotion of adsorption depends on the concentration of organic acids. For example, in an acidic environment $(\mathrm{pH}$ $=5$ ), a lower concentration of organic acids can promote the adsorption of heavy metals by goethite, whereas a higher concentration of organic acids can inhibit the adsorption reaction [27]. Whether the addition of root exudates promotes or inhibits the removal of heavy metals in the groundwater environment is greatly affected by the type of plant, the type of iron oxide mineral, the type and concentration of heavy metal ions, and the environmental conditions of the interaction.

Heavy metal solubility and bioavailability can be enhanced by microorganisms, thereby making microbial remediation an effective means of heavy metal removal from the environment [28-30]. Previous studies have shown that soluble organic matter affects the mobility of arsenic in different ways. Regarding the soil environment, dissolved organic matter from root exudates affects the distribution and morphological classification of arsenic in the rhizosphere. For example, in the rhizosphere, the root exudates of the arsenic-enriched plant yarrow activate insoluble iron arsenate, aluminum arsenate, and fixed arsenic, which exist in copper arsenic tailing-contaminated soil [31]. This process causes 
the distribution of arsenic in the rhizosphere to be deficient [32]. Microbial communities such as Pseudomonas sp. LK9 affect the secretion of lowmolecular-weight organic acids that can be combined with heavy metals [33,34]. Humic acid, fulvic acid, and the soil mineral surface are strongly bound [35], therefore the binding sites of arsenic are blocked $[36,37]$. When root exudates are continuously transferred and released into the groundwater environment, they also affect the migration and transformation of arsenic in the groundwater environment.

\section{CONCLUSION}

In this study, alfalfa root exudates were extracted. The basic properties of the root exudates were characterized. The three-dimensional fluorescence spectroscopy (excitation-emission matrix) results showed that the exudates contained aromatic proteins derived from tyrosine, substances derived from tryptophan, and substances derived from humic acids. The addition of root exudates promotes the oxidation of Fe(II), the degradation of nitrate, and the removal of heavy metals by Clostridium sp. strain PXL2. The complexation between Fe(III) and the root exudates was analyzed by quenching titration. The results showed that the fluorescence quenching of root exudates includes both dynamic and static quenching. The addition of root exudates is beneficial to promote the oxidation of ferrous iron, the degradation of nitrate, and the removal of As and $\mathrm{Hg}$ by the Clostridium sp. strain PXL2.

Acknowledgements: This work was supported by the Tianshan Youth Program of Xinjiang Uygur Autonomous Region, China (2017Q035).

\section{REFERENCES}

1. Zeng YY, Zhou JL, Zhou YZ, Jia RL (2016) Assessment and causes of groundwater organic pollution in typical plain areas in Xinjiang, China. Expo Health 8, 401-417.

2. Shan GB, Surampalli RY, Tyagi RD, Zhang TC (2009) Nanomaterials for environmental burden reduction, waste treatment, and nonpoint source pollution control: A review. Front Environ Sci Eng China 3, 249-264.

3. Widdel F, Schnell S, Heising S, Ehrenreich A, Assmus B, Schink B (1993) Ferrous iron oxidation by anoxygenic phototrophic bacteria. Nature 362, 834-836.

4. Weber KA, Urrutia MM, Churchill PF, Kukkadapu RK, Roden EE (2006) Anaerobic redox cycling of iron by freshwater sediment microorganisms. Environ Microbiol 8, 100-113.
5. Schaedler F, Lockwood C, Lueder U, Glombitza C, Kappler A, Schmidt C (2018) Microbially mediated coupling of $\mathrm{Fe}$ and $\mathrm{N}$ cycles by nitrate-reducing $\mathrm{Fe}(\mathrm{II})$-oxidizing bacteria in littoral freshwater sediments. Appl Environ Microbiol 84, 13-17.

6. Warembourg F, Billes G (1979) Estimating carbon transfer in the rhizosphere. In: Harley JL, Russel RS (eds) The Soil-Root Interface, Academic Press, New York, pp 183-197.

7. Umaru FF, Owuama CI (2018) Application of plantmicrobe interactions in contaminated agroecosystem management. In: Kumar V, Kumar M, Prasad R (eds) Phytobiont and Ecosystem Restitution, Springer, Singapore, pp 63-100.

8. María ZSS, Nadia L, Jose SDC, Claudia SB, Marta AP, Analia A (2019) Multi-resistant plant growthpromoting actinobacteria and plant root exudates influence $\mathrm{Cr}(\mathrm{VI})$ and lindane dissipation. Chemosphere 222, 679-687.

9. Montiel-Rozas MM, Madejón E, Madejón P (2016) Effect of heavy metals and organic matter on root exudates (low molecular weight organic acids) of herbaceous species: An assessment in sand and soil conditions under different levels of contamination. Environ Pollut 216, 273-281.

10. Habibul N, Hu Y, Wang YK, Chen W, Yu HQ, Sheng GP (2016) Bioelectrochemical chromium(VI) removal in plant-microbial fuel cells. Environ Sci Technol 50, 3882-3889.

11. Slanina J, Lingerak WA, Bergman L (1976) A fast determination of nitrate in rain and surface waters by means of UV spectrophotometry. Z Anal Chem 280, 365-368.

12. Geng YJ, Wu Q, Muszynski M, Hansson GK, Libby P (1996) Apoptosis of vascular smooth muscle cells induced by in vitro stimulation with interferon- $\gamma$, tumor necrosis factor- $\alpha$, and interleukin-1 $\beta$. Arterioscler Thromb Vasc Biol 16, 19-27.

13. Gendel Y, Lahav O (2008) Accurate determination of $\mathrm{Fe}(\mathrm{II})$ concentrations in the presence of a very high soluble Fe(III) background. Appl Geochem 23, 2123-2129.

14. Baohua Li, Chunnuan D, Daoyong Z, Xiangliang P, Fahad AA, Mortuza MG (2016) Bioremediation of nitrate- and arsenic contaminated groundwater using nitrate dependent Fe(II) oxidizing Clostridium sp. strain pxl2. Geomicrobiol J 33, 185-193.

15. Klueglein N, Kappler A (2013) Abiotic oxidation of $\mathrm{Fe}$ (II) by reactive nitrogen species in cultures of the nitrate-reducing $\mathrm{Fe}$ (II) oxidizer Acidovorax sp. BoFeN1-questioning the existence of enzymatic Fe(II) oxidation. $J$ Geobiol 11, 180-190.

16. Coble PG (1996) Characterization of marine and terrestrial DOM in seawater using excitation-emission matrix spectroscopy. Mar Chem 51, 325-346.

17. Baker A, Genty D (1999) Fluorescence wavelength and intensity variations of cave waters. J Hydrol 217, 
19-34.

18. Chen W, Westerhoff P, Leenheer JA, Booksh K (2003) Fluorescence excitation-emission matrix regional integration to quantify spectra for dissolved organic matter. Environ Sci Technol 37, 5701-5710.

19. Saxena G, Purchase D, Mulla SI, Saratale GD, Bharagava RN (2019) Phytoremediation of heavy metal-contaminated sites: Eco-environmental concerns, field studies, sustainability issues, and future prospects. Rev Environ Contam T 249, 71-131.

20. Lakowicz JR (2006) Principles of Fluorescence Spectroscopy, 3rd edn, Springer, New York, USA.

21. Hill TL (1985) Cooperativity: Theory in Biochemistry, Springer-Verlag, New York, NY.

22. Liu SM, Yang B, Liang YS, Xiao YH, Fang J (2020) Prospect of phytoremediation combined with other approaches for remediation of heavy metal-polluted soils. Environ Sci Pollut Res 27, 16069-16085.

23. Lackovic K, Angove MJ, Wells JD, Johnson BB (2004) Modeling the adsorption of Cd(II) onto goethite in the presence of citric acid. J Colloid Interface Sci 269, 37-45.

24. Collins CR, Ragnarsdottir KV, Sherman DM (1999) Effect of inorganic and organic ligands on the mechanism of cadmium sorption to goethite. Geochim Cosmochim Acta 63, 2989-3002.

25. Elliott HA, Denneny CM (1982) Soil adsorption of cadmium from solutions containing organic ligands. $J$ Environ Qual 11, 658-662.

26. Liao M (2006) Effects of organic acids on adsorption of cadmium onto kaolinite, goethite, and bayerite. Pedosphere 16, 185-191.

27. Harter RDR, Naidu R (1995) Role of metal-organic complexation in metal sorption by soilse. Adv Agron 55, 219-264.

28. Giller KE, Witter E, Mc Grath SP (2009) Heavy metals and soil microbes. Soil Biol Biochem 41, 2031-2037.

29. Lorenz N, Hintemann T, Kramarewa T, Katayama A,
Yasuta T, Marschner P, Kandeler E (2006) Response of microbial activity and microbial community composition in soils to long-term arsenic and cadmium exposure. Soil Biol Biochem 38, 1430-1437.

30. Al-Hagar OEA, Bayoumi RA, Aziz OAA, Mousa AM (2020) Biosorption and adsorption of some heavy metals by Fusarium sp. F6c isolate as affected by gamma irradiation and agricultural wastes. ScienceAsia 46, 37-45.

31. Tu S, Ma L, Luongo T (2004) Root exudates and arsenic accumulation in arsenic hyperaccumulating Pteris vittata and non-hyperaccumulating Nephrolepis exaltata. Plant Soil 258, 9-19.

32. Fitz WJ, Wenzel WW, Zhang H, Nurmi J, Stipek K, Fischerova Z, Schweiger P, Kollensperger G, et al (2003) Rhizosphere characteristics of the arsenic hyperaccumulator Pteris Vittata L. and monitoring of phytoremoval efficiency. Environ Sci Technol 37, 5008-5014.

33. Ayangbenro AS, Babalola OO (2018) Metal(loid) bioremediation: Strategies employed by microbial polymers. Sustainability 10, ID 3028.

34. Jing R, Kjellerup BV (2018) Biogeochemical cycling of metals impacting by microbial mobilization and immobilization. $J$ Environ Sci 66, 146-154.

35. Kaiser K, Guggenberger G, Haumaier L, Zech W (1997) Dissolved organic matter sorption on subsoils and minerals studied by 13C-NMR and DRIFT spectroscopy. Soil Sci 48, 301-310.

36. Grafe M, Eick MJ, Grossl PR, Saunders AM (2002) Adsorption of arsenate and arsenite on ferrihydrite in the presence and absence of dissolved organic carbon. Environ Qual 31, 1115-1123.

37. Redman AD, Macalady DL, Ahmann D (2002) Natural organic matter affects arsenic speciation and sorption onto hematite. Environ Sci Technol 36, 2889-2896. 